\title{
Effect of High Level Penetration of Grid Connected Photovoltaic to the Low Voltage Side of the Power System in UK
}

\author{
Safaa Abdulhussein Hasson Al-Abboodi \\ Ministry of Electricity, \\ General Company of Electricity for middle
}

\begin{abstract}
This paper analyze the voltage profiles in power distribution networks with different levels of small-scale PV systems. The grid-connected PV system is one of the most promising renewable energy solutions which could offer many benefits to both the end user and the utility network, adistribution network model has been developed in MATLAB/Simulink and implemented to evaluate the voltage profiles and power flow for different levels of PV systems. This will help in evaluating the impact of high penetration levels of small-scale grid connected PV systems on the power quality for a residential distributed network in the UK. Different penetration scenarios and variable load conditions are considered. The result obtained confirmed that maintaining a stable operation and an acceptable power quality in distribution networks are possible with a wide range of PV penetration levels.
\end{abstract}

Keywords:

\section{INTRODUCTION}

One of the big challenges are facing the energy sector are increasing energy demands while primary energy sources are limited. Existing power plants are rely mainly on fossil fuels (oil, gas and coal), which has a negative impact to the environment[1,2]. To overcome these drawbacks, the European commission proposed a new energy policy in 2007 based on distributed generation to reduce the emission of greenhouse gases, improve power quality and increase the contribution of sustainable power sources such as Wind turbine generator and $\mathrm{Pv}$ system. However[1,3,4], integration of renewable energy sources to the utility grid introduces a new set of challenges[5,6,7]. As well as, traditional power system is designed as a unidirectional power system, penetration of renewable energy sources at different points of power system require bidirectional power flow and that leading to protection problems $[8,6,9,10]$. The photovoltaic system and especially (Grid-connected GCPV) are also becoming more prominent during the last few decades[11,12,13]. A typical daily load profile and the output power of $3 \mathrm{Kw}$ PV system are considered (summer season). The main issue are expected to be happen is the overvoltage ( demand low and generation penetration is high) $[3,8,9]$.

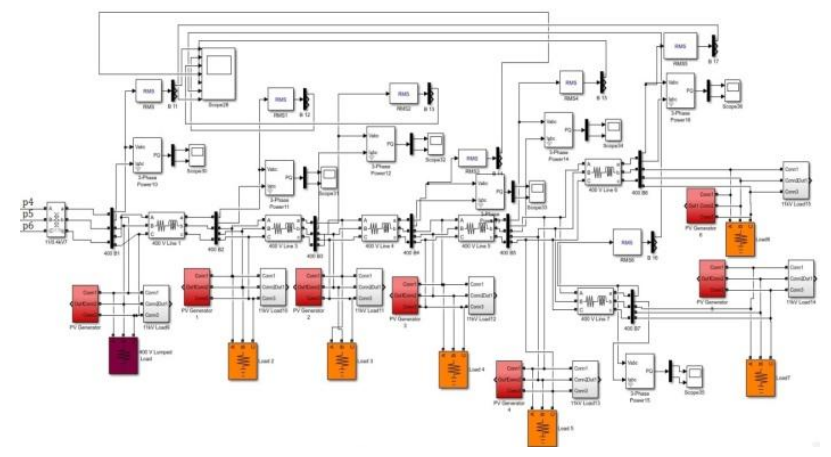

Figure(1): Schematic Diagram of Computer Models (Low voltage side)

\section{METHODOLOGY}

\subsection{Simulation of the UK Distribution Network model}

The system modelled by using MATLAB/Simulink simpower system toolbox, the nominal primary voltage is setting to $33 \mathrm{kV}$ and supplied to Bus 1 . Bus 2 connect to the AC distributed energy sources. Distribution substation in the UK includes two three-phase OLTC regulating transformers rated at $20 \mathrm{MVA}, 33 \mathrm{Kv} / 11.5 \mathrm{kV}$ type Wye/ Delta. In general, OLTC is located at the primary side of the transformers because of the current will be too less than the current in the secondary side to reduce the spark through transfer between the position of the tap changer. It supplied by medium voltage range 66 or $33 \mathrm{kV}$. The OLTC transformers are used to regulate the system voltage at Bus 2 , which is require to change the turn ratio of the transformer. Typical frequency in the UK is setting at 50HZ. The OLTC performed by eight series regulation winding (tapped winding) for each phase. Each phase of the regulating tap windings connected in series with each 11.5/sqrt (3) $\mathrm{kV}$ winding. There is inside the OLTC a reversing switch enables reversing connections of the regulation winding. Accordingly, there are Nine OLTC switches works with 17 taps; Zero position, which provides the nominal transformer ratio $33 \mathrm{kV} / 11.5 \mathrm{kV}$, eight negatives (eight subtractive position 1-8) and eight positives (eight additive position 1-8).

The OLTC contained a reverse switching to permit the reverse connection of the regulation winding, which is also connected to \pm 8 tap positions.

Each tap in the low voltage side $11.5 \mathrm{kV}$ will maintain a voltage correction of $\pm 0.0167 \mathrm{pu}$ or $\pm 1.67 \%$ of the rated primary voltage $33 \mathrm{kV}$, as a result, a total of 17 tap positions will permit the variation in voltage by steps of $0.0167 \mathrm{pu}(0.55 \mathrm{kV})$

The tap changer time response is 5 secs per tap and this is limited by the OLTC controller. As OLTC voltage regulation varied accordingly with a transformer ratio which has a specified dead zone. 
The OLTC dead zone $\left(\mathrm{DZ}_{\mathrm{OLTC}}=(2)(\right.$ STEP VOLTAGE $)$

Where

Step voltage $=$ Step voltage per tap (per unit)

Therefore, the voltage regulator of the OLTC orders further voltage boosting and stabilises the voltage within a maximum voltage error (which is equal to step voltage), and hence the maximum and minimum permitted of the OLTC is given as:

$$
\mathrm{v}_{\text {ref }}-\left(\frac{\mathrm{DZ}}{2}\right)<V<\mathrm{V}_{\text {initialtapposition }}+\left(\frac{\mathrm{DZ}_{\mathrm{OLTC}}}{2}\right)
$$

Where

$\mathrm{v}_{\mathrm{ref}}=$ Reference voltage for the OLTC (per unit)

$\mathrm{V}_{\text {intialtapposition }}=$ Voltage at initial tap position (per unit)

The maximum and minimum voltage errors per tap changing is set to $(0.9875$ to 1.0125 per unit) respectively, as the OLTCs value of $\mathrm{DZ}_{\text {OLTC }}$ has set as 0.025 per unit, and the voltage reference is considered as 1 for each unit.

All distribution transformers had ratio $11 / 0.433 \mathrm{kV}$, connected at tap $0 \%$. On a base of 230/400 V. Short circuit level was $500 \mathrm{e} 3$ and setting frequency at $50 \mathrm{HZ}$.

Dynamic load emulates as a subsystem block model as shown in Appendix A, Figure 33-A), it includes a lookup table which provide the three phase dynamic load by the required $\mathrm{P}$ and $\mathrm{Q}$. Active power $\mathrm{P}$ calculated by multiplying the apparent power per 24 hours (Winter and Summer ADMD) by the value of the power factor which supposed (0.95). As well as, reactive power calculated by multiplying the apparent power by the constant which is $\left(\sin ^{-1} \cos 0.95\right)$.

Domestic PV system output profiles emulates as a subsystem as shown in Appendix A, Figure 33-B), it includes a lookup table which provide the three phase dynamic load by active power only. PV generation values represents inside the lookup table by negative values.

Diesel generator sets emulates as a diesel engine coupled to a synchronous machine as an isolated power source requirements or in scenarios where sudden demand are expected as shown in Appendix B, Figure 34.

\section{MODEL SIMULATION WITH DYNAMIC LOAD WITH DIFFERENT PV PENETRATION}

Voltages at different nodes of the distribution network corresponding to the daily load and PV generation profile for a domestic load in the UK adopted.

Domestic PV system output profiles specification for winter and summer was as:

- Winter: generated from the measured output of a domestic PV system in the UK for the months of December, January and February.

- Summer: generated from the measured output of a domestic PV system in the UK for the months of June, July and August.
- System size is $2.03 \mathrm{KW}$, tilt angle 30 degrees, azimuth angle 0 degrees (south facing), output in Wh (average Wh generated in that hour)-average are calculated for the hour centered on the value, i.e. 10 values are the average output between 9:30 and 10:30.

Many scenarios are achieved by the penetration of the PV on the low voltage side $230 / 400 \mathrm{~V}$ which are $25 \%, 50 \%$ and $100 \%$ to each node of the model for a summer and winter profile.

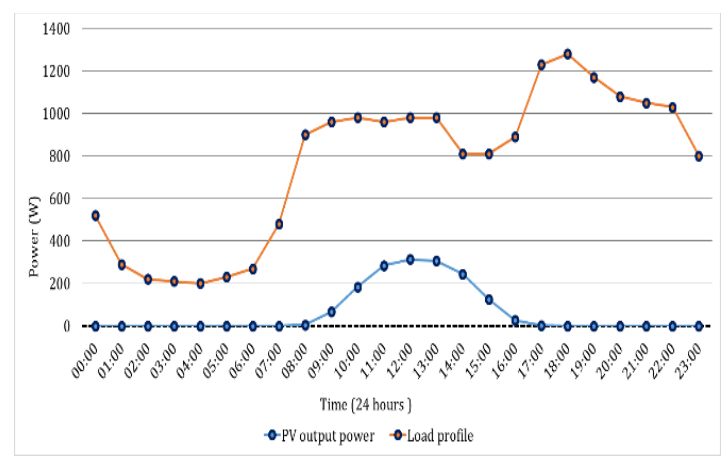

A- Winter season

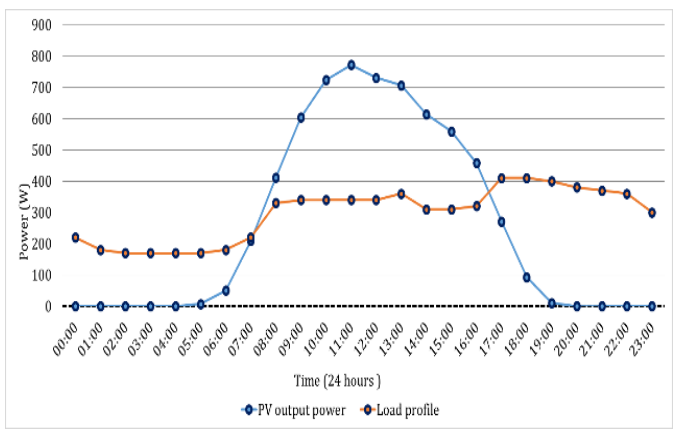

B-Summer season

Figure 1: Typical daily load profile and PV output power

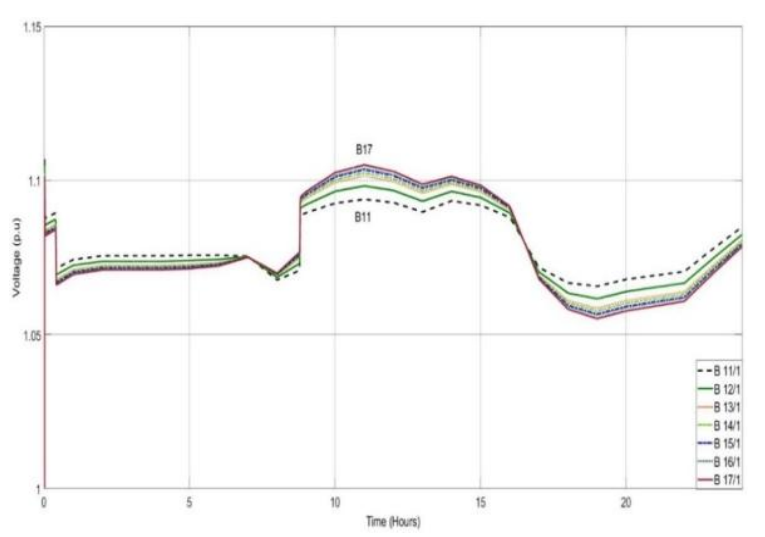

Figure 2: Voltage profile along the $230 / 400 \mathrm{~V}$ feeder with 100 $\% \mathrm{PV}$ penetration level in summer (Off-load tap changer) 


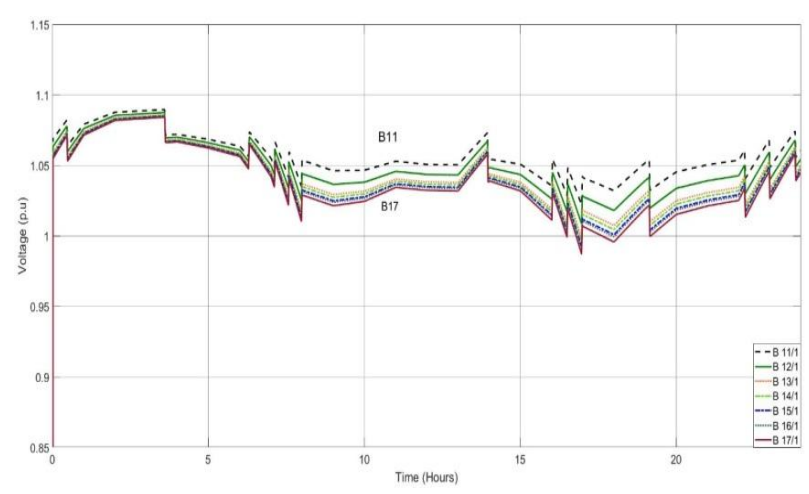

Figure 3: Voltage profile along the $230 / 400 \mathrm{~V}$ feeder with $100 \% \mathrm{PV}$ penetration level in winter (On-load tap changer)

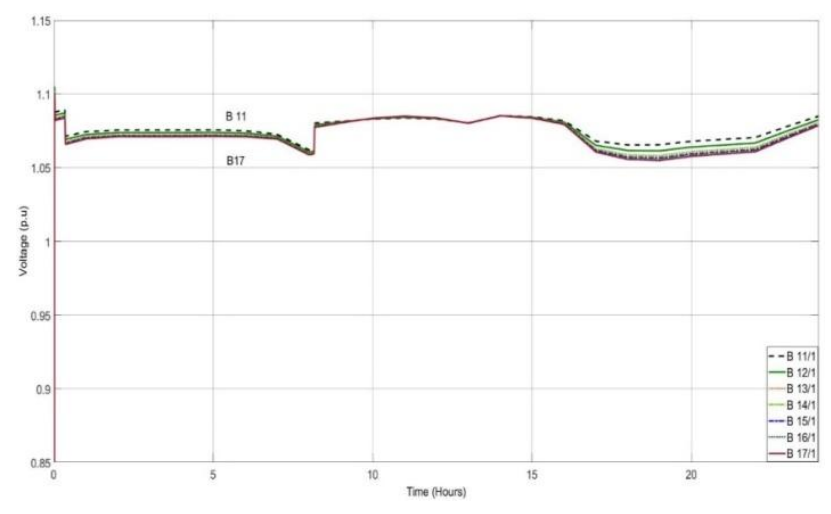

Figure 4: Voltage profile along the $230 / 400 \mathrm{~V}$ feeder with $50 \%$ PV penetration level in summer (On-load tap changer)

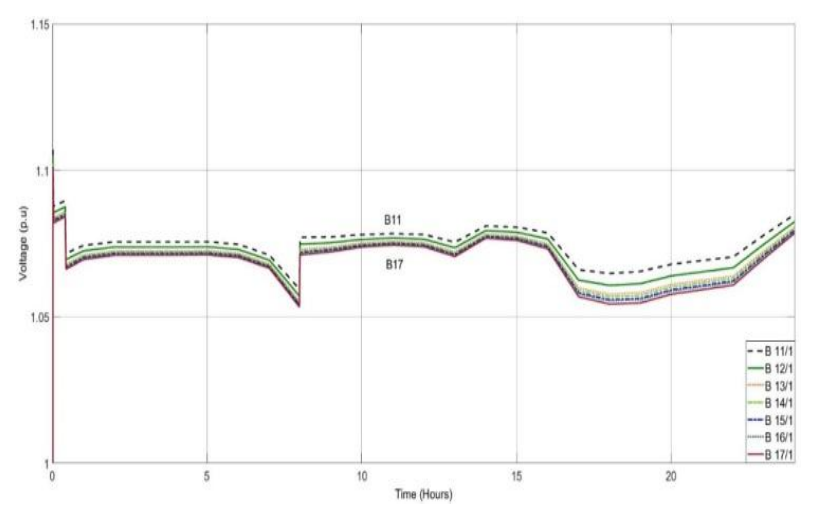

Figure 5: Voltage profile along the $230 / 400 \mathrm{~V}$ feeder with $25 \%$ PV penetration level in summer (On-load tap changer)

\section{CONCLUSION}

A distribution network model has been implemented and developed in to evaluate the voltage profiles and power flow for different levels of PV systems (25\%, 50\%, 100\%) penetration. It was noticed that even with connecting PV to whole customers $(25 \%, 50 \%, 100 \%)$ penetration in winter, and for $(25 \%, 50 \%)$ penetration in summer, the voltage profile sustains on the allowable limits. However, with $100 \%$ penetration, the voltage profile exceeds the statuary limit through the period between (10 AM to $2 \mathrm{PM}$ ) in summer where the penetration is $100 \%$, which is considered the best period for PV generation. The challenge in the renewable distributed generation will be happen when the demand is low, and the penetration level is high, as there might be a bi-directional power flowing according to the location and the capacity of generator, accordingly, these variations can be controlled by utilizing the energy storage systems such as batteries and electric vehicle (EVs) to support the grid by providing the energy when there is a mismatch between the load and the generation. In addition, to save the energy when there is surplus in the generation as compared with demands (particularly in summer season).

\section{REFERENCES}

[1] PALZBON, O., KAWhNi,EMI K. \& GUERRERO, J. M. 2014. Microgrids in active network management-Part I: Hierarchical control, energy storage, virtual power plants, and market participation. Renewable and Sustainable Energy Reviews, 36, 428-439.

[2] PEI, Y., JIANG, G., YANG, X. \& WANG, Z. Automaster-slave control technique of parallel inverters in distributed AC power systems and UPS. Power Electronics Specialists Conference, 2004. PESC 04. 2004 IEEE 35th Annual, 2004. IEEE, 2050-2053.

[3] PIAGI, P. \& LASSETER, R. H. Autonomous control of microgrids. Power Engineering Society General Meeting, 2006. IEEE, 2006. IEEE, 8 pp.

[4] RUA, D., PEREIRA, L. M., GIL, N. \& LOPES, J. P. Impact of multi-microgrid communication systems in islanded operation. Innovative Smart Grid Technologies (ISGT Europe), 2011 2nd IEEE PES International Conference and Exhibition on, 2011. IEEE, 1-6.

[5]SALOMONSSON, D., SODER, L. \& SANNINO, A. An adaptive control system for a DC microgrid for data centers. Industry Applications Conference, 2007. 42nd IAS Annual Meeting. Conference Record of the 2007 IEEE, 2007. IEEE, 2414-2421.

[6] SIDDIQUI, A. S., MARNAY, C., EDWARDS, J. L., FIRESTONE, R., GHOSH, S. \& STADLER, M. 2005. Effects of carbon tax on microgrid combined heat and power adoption. Journal of Energy Engineering, 131, 225.

[7] Tushar, M. (2017). Unveiling the Hidden Connections between E-mobility and Smart Microgrid - Optical Zeitgeist Laboratory. [online] Zeitgeistlab.ca. Available at: 
[8]http://www.zeitgeistlab.ca/doc/Unveiling_the_Hidden_Connec tions_between_E-mobility_and_Smart_Microgrid.html

[Accessed 15 Sep. 2017].

[9] VASQUEZ, J. C., GUERRERO, J. M., MIRET, J., CASTILlA, M. \& DE VICUNA, L. G. 2010. Hierarchical control of intelligent microgrids. IEEE Industrial Electronics Magazine, 4, 23-29.

[10]VISSCHER, K. \& DE HAAN, S. W. H. Virtual synchronous machines (VSG's) for frequency stabilisation in future grids with a significant share of decentralized generation. SmartGrids for Distribution, 2008. IET-CIRED. CIRED Seminar, 2008. IET, 1-4.

[11]XINCHUN, L., FENG, F., SHANXU, D., YONG, K. \& JIAN, C. The droop characteristic decoupling control of parallel connected UPS with no control interconnection. Electric Machines and Drives Conference, 2003. IEMDC'03. IEEE International, 2003. IEEE, 1777-1780.

[12]YAJUAN, G., WEIYANG, W., XIAOQIANG, G. \& HERONG, G. An improved droop controller for gridconnected voltage source inverter in microgrid. Power Electronics for Distributed Generation Systems (PEDG), 2010 2nd IEEE International Symposium on, 2010. IEEE, 823-828.

[13]ZAMORA, R. \& SRIVASTAVA, A. K. 2010. Controls for microgrids with storage: Review, challenges, and research needs. Renewable and Sustainable Energy Reviews, 14, 2009-2018.

[14]ZHANG, Z., HUANG, X., JIANG, J. \& WU, B. 2010. A load-sharing control scheme for a microgrid with a fixed frequency inverter. Electric power systems research, 80, 311-317.

[15]ZHONG, Q.-C. \& WEISS, G. Static synchronous generators for distributed generation and renewable energy. Power Systems Conference and Exposition, 2009. PSCE'09. IEEE/PES, 2009. IEEE, 1-6. 